\title{
Screening of adverse childhood experiences in preschoolers: a systematic review
}

\author{
Maribel Vega-Arce ${ }^{1 *}$ and Gastón Núñez-Ulloa ${ }^{2}$ \\ ${ }^{1}$ Universidad Católica del Maule, Talca; ${ }^{2}$ Escuela de Lenguaje, San Clemente. Chile
}

\begin{abstract}
The present review aims to describe scientific publications available that detail strategies and screening tools for adverse childhood experiences in preschoolers (2 to 5 years of age). A systematic review of the topic was carried out through research articles published in peer-reviewed journals from January 1998 to June 2017 and indexed in seven international databases (Cochrane Library, EBSCO, PubMed, Science Direct, Springer, Web of Science and Scielo). The articles were selected based on predefined criteria, using limiters and manual screening. Twenty articles published between 1999 and 2017 were selected. The screening of adverse childhood experiences is performed through opportunistic recruitment in a professional context aimed at caregivers and children, which integrates training actions, application of screening tools, and reception of identified cases. Screening tools differ between interviews and questionnaires. In addition, we report the periodicity of the screening, the behaviors, and beliefs of the professionals against it and the barriers to its implementation. This review confirms that the screening of adverse childhood experiences is an emerging topic in the research field. We emphasize the need to systematize and evaluate the strategies and tools for screening adverse childhood experiences, as well as to develop local approaches to respond to the needs of children exposed to adversity.
\end{abstract}

Key words: Childhood. Psychosocial factors. Systematic review.

\section{Cribado de las experiencias adversas en la infancia en preescolares: revisión sistemática}

\section{Resumen}

El presente artículo busca describir las publicaciones científicas que detallan estrategias y herramientas de cribado del parámetro experiencias adversas en la infancia, disponibles para población preescolar (2 a 5 años). Para esto, se realizó una revisión sistemática exploratoria del tema a través de artículos de investigación publicados en revistas de revisión por pares entre enero de 1998 y junio de 2017 e indexados en siete bases de datos internacionales (Biblioteca Cochrane, EBSCO, PubMed, Science Direct, Springer, Web of Science y Scielo). Los artículos fueron seleccionados con base en criterios predefinidos, haciendo uso de limitadores y tamización manual. En total, se seleccionaron 20 artículos publicados entre 1999 y el 2017. El cribado de las experiencias adversas en la infancia se realiza por medio de una captación oportunista en un contexto profesional orientado a los cuidadores y niños, que integra acciones de capacitación, aplicación de herramientas de tamización y acogida de los casos identificados. Las herramientas de cribado se diferencian entre entrevistas y

\section{Correspondence:}

*Maribel Vega-Arce

Email: mvega@ucm.cl
Available online: 25-06-2018 Bol Med Hosp Infant Mex. 2017;74:383-393

www.bmhim.com 
cuestionarios. De igual modo, se reporta la periodicidad del cribado, los comportamientos y creencias de los profesionales frente a este y las barreras para su implementación. La revisión realizada confirma que el cribado de las experiencias adversas en la infancia es una temática emergente en el ámbito investigativo. Se hace énfasis en la necesidad de sistematizar y evaluar las estrategias y herramientas para cribado de las experiencias adversas en la infancia, así como desarrollar aproximaciones locales que permitan responder a las necesidades de los niños expuestos a adversidad.

Palabras clave: Infancia. Factores psicosociales. Revisión sistemática.

\section{Introduction}

In recent years, the parameter adverse childhood experiences (ACE) has become a benchmark in research on the early impact of stress on child development. ${ }^{1}$ Its use has been extended in a context of awareness of the extent of the mistreatment of children, ${ }^{2,3}$ as well as the severity of the consequences of exposure to multiple victimizations. ${ }^{4}$

ACE include different non-normative events, such as physical or psychological abuse, sexual abuse, negligence, witnessing interfamily violence, substance abuse by a family member, separation or divorce of the parents, mental illness or incarceration of a family member. ${ }^{5}$ Over time, these categories have been expanded, including social factors ${ }^{6}$ and other types of commonly experienced adversities during childhood. ${ }^{7}$

Several studies have allowed us to conclude that ACEs operate as a conglomerate with cumulative impact and dose-response effect. Four or more ACEs are associated with the primary risk factors for morbidity and mortality in adulthood. ${ }^{8,9}$ There is evidence on the association of ACEs and cancer, ${ }^{10}$ type 2 diabetes, ${ }^{11}$ depression ${ }^{12}$, suicide attempts, post-traumatic stress, addictions, ${ }^{13}$ psychosis, ${ }^{14}$ among other problems. These findings have led us to consider ACEs as a milestone of prevention in health. ${ }^{15}$

Retrospective research carried out in adults indicates that ACEs are frequent and co-occurring. ${ }^{9,16}$ In preschoolers, it is estimated that over $60 \%$ have experienced at least one $\mathrm{ACE}^{17}$ and $12.5 \%$ have experienced two or more. ${ }^{18}$ The first ACE occurs in the first year and a half of life, ${ }^{19}$ and may signify the child's entry into a risks spiral. In this regard, Dong et al. ${ }^{20}$ establish that the exposure to an event increases between 2 and 18 times the probability of suffering another type of adversity.

The intergenerational transmission of $\mathrm{ACEs}^{21,22}$ is related to the parent's complications, which have experienced adversity early in the exercise of their role, and may involve greater stress ${ }^{23}$ and hostility toward their preschooler children. ${ }^{24}$ The exposure of children $<5$ years of age to intense and diverse ACEs in the absence of stable and protective bonds that support healthy adaptation ${ }^{25}$ is associated with toxic stress, ${ }^{26}$ and may have an unfavorable impact on their development, health, and education. ${ }^{27}$ Therefore, it has been recommended early detection of factors that may pose a higher risk for small children. ${ }^{28}$

The screening tools for potentially traumatic situations meant for children have the purpose of detecting the exposure to these types of events and the possible reactions to these experiences. Screening is the initial step of a systematic process aimed at assessing the condition in asymptomatic people. If positive, it allows focusing the diagnosis, and eventually, recommending an appropriate treatment plan. ${ }^{29}$ In general, brief and universal evaluations ${ }^{30}$ guided by several core principles to identify social determinants, such as favoring a conversation with parents in routine appointments for the expression of their concerns, recognize risk and protection factors in children and families, detect specific problems, and refer those for future diagnosis with the corresponding professionals. $^{31}$

Screening ACEs in preschool children becomes relevant because of the excellent results from early interventions aimed at strengthening their environments. ${ }^{32}$ In this regard, the development of screening programs supported by standardized tools is recommended as a priority of the work with children. ${ }^{33}$ However, no consensus exists on the best way to detect the psychosocial problems that affect families with young children. ${ }^{34}$ In primary care, some programs incorporate universal screening of the ACE, ${ }^{35}$ while other professionals manage to identify and successfully manage ACEs as part of their routine or to establish alliances with departments in case of a patient detection. ${ }^{33}$

Defining screening options for ACE as precipitants of toxic stress - the most severe response in the absence of an effective reliever-is part of the challenges in a scenario in which children's physical health is closely linked to their mental and social well-being. ${ }^{36}$ This review aimed to describe the available data that detail strategies and screening tools of the available ACEs parameter for the preschool population (2 to 5 years of age), to illustrate the approaches used in the general evaluation of these risk factors. 


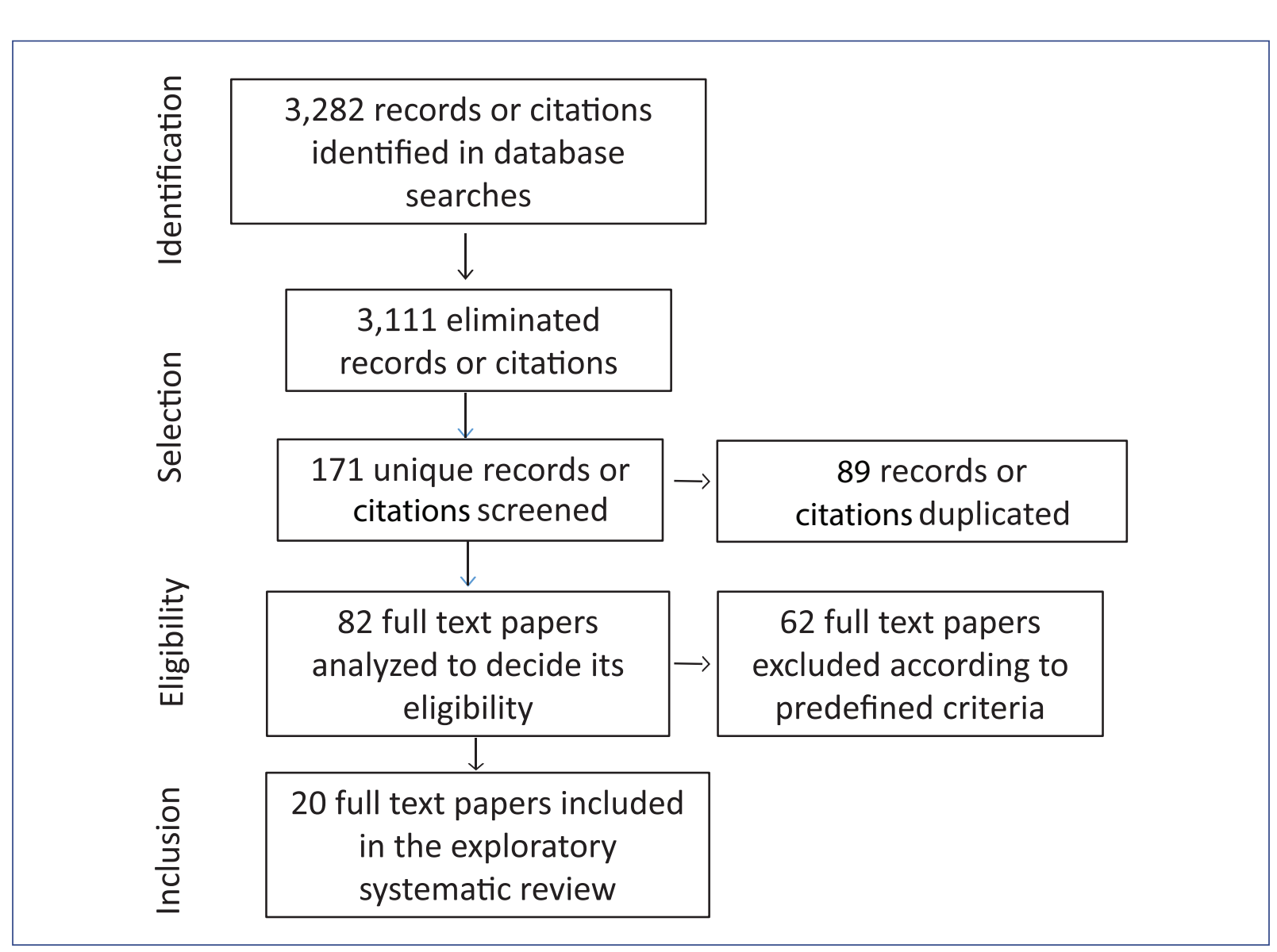

Figure 1. The systematic process for the selection of articles.

\section{Methods}

A review of the literature was carried out through an exploratory systematic review methodology. ${ }^{37}$ This type of study synthesizes the scientific evidence about a health subject, allowing to develop emerging areas of study. ${ }^{38}$

The search was conducted through the consultation to the following databases: Cochrane Library, EBSCO (AcademicSearchComplete, CINAHLComplete, EducationSource, MEDLINE, MEDLINE Complete and Psychology and Behavioral Sciences Collection), PubMed, Science Direct Springer, Web of Science and Scielo.

The search terms were "adverse childhood experiences" and "life events", combining "screen", "assess", "pediatric", and "paediatric" with the Boolean operators "AND» and "OR». The search was completed from October 2016 until June 2017.

The inclusion criteria used were the following:

a) Research published in refereed journals

b) The publication period between January 1998 to June 2017. This restriction was established based on the year of publication of the seminal article of the ACEs parameter ${ }^{9}$ and the search date in the databases c) The ACEs parameter is used in the screening of children between 2 and 5 years of age

d) The strategy or the used screening tool is described In contrast, the exclusion criteria were as follows:

a) Narrative reviews, book chapters, editorials, comments, letters to the editor or articles with subsequent retraction and posters

b) Articles or chapters with inaccessible full text

c) No restrictions were established in the language of publication

The article selection process comprised four phases (Fig. 1):

1. Identification of the articles through databases and the selected paper references

2. Selection. The title, summary, keywords and, year of each article were reviewed. Through a manual screening, the papers that did not meet the search criteria and those duplicated were eliminated

3. Eligibility. Subsequently, one of the researchers extracted the data from all the texts and then, independently, assessed their relevance according to the objective of our research, guided by the full-text article 
4. Inclusion of eligible articles in the systematic exploratory review

The selected papers were synthesized and characterized according to their bibliometric variables (author, publication year, country, type, language, and journal) their objectives, results, and theme in ACEs screening.

Subsequently, we proceeded to the analysis according to the data mapping technique by Arksey and O'Malley for systematic exploratory reviews. ${ }^{37}$ This approach seeks to synthesize and interpret qualitative data through a systematic process consisting of the definition of a thematic structure that arises from the papers included in the study, and the subsequent screening, mapping, and classification of data, allowing the definition of an analytical framework according to the objective. ${ }^{38,39}$ The extraction of the data from the screening tools had to be complemented to specify its general characteristics and confirm its applicability to the preschool population. ${ }^{40}$ Subsequently, a categorical analysis was carried out according to the convergences and divergences found in the extracted material, as well as a global analysis of the information.

\section{Results}

Twenty academic articles that detail strategies and screening tools of the ACEs parameter available for preschool population (2 to 5 years old) were selected. Table 1 describes those that were included in this review, indicating the name of the main author, objective, year, country, type of publication, language, and journal. ${ }^{41-60}$

The origin of the selected articles corresponds to the United States $(80 \%)$, the Netherlands $(10 \%)$, Colombia $(5 \%)$ and Israel-USA (5\%). In total, 90 authors were identified, ranging from 1-8 in the different publications. Of these, 12 presented authorship in more than one selected article. The totality of the data was published between 1999 and 2017, with an increase in the volume of articles from 2013 to date, which allows us to infer a growing interest in studying this phenomenon. From 1999 to 2011, all authors come from the USA. However, from 2012, the country of origin of the authors diversified.

The categorical analysis reveals that the papers give relevance to the screening of the ACE due to its harmful effects in the child development, ${ }^{46,48,49,54-58,60}$ as a precipitating factor for toxic stress $42,43,47,50,56,59$ or as a source of childhood stress. ${ }^{41,44,51-53}$

The theme addressed is focused on four aspects: the selective screening directed to a group of high risk $^{41,42,44,46,48,51,53,55,56,60}$ and the evaluation of a screening tool, $44,52,54,57,58$ the professional role in early clinical detection (case finding), ${ }^{43,50,53,59}$ and the universal screening of adversities. ${ }^{45,47,49}$

Of the 20 selected articles, four refer to screening strategies, $41,49,50,59$ seven report or use screening tools, ${ }^{42,46,48,52,53,57,58}$ and nine consider both screening strategies and tools for this purpose. ${ }^{43-45,47,51,54-56,60}$ Except for the article by Flynn et al., ${ }^{45}$ which corresponds to a systematic review, the rest is quantitative research about the studied phenomenon. . $^{4-44,46-60}$

\section{ACE screening strategies}

The articles recognize ACE screening strategies in preschoolers as part of a fundamental role in their care. Table 2 lists the thirteen articles that address targeted screening strategies in preschool population, considering the type of study, sample, and conclusions on the subject.

In general, the screening strategy is oriented to a opportunistic, universal $41,43,47,50,59$ or selecti$\mathrm{ve}^{4,45,49,51,54-56,60}$ detection. The universal screening comes from a validated and daily professional platform in the environment of families, such as the physician's pediatric care, $, 1,43,47,50,59$ professionals of first level health care units ${ }^{45,52,53}$ or through the education system. ${ }^{60}$ In the selective screening, users are captured in scenarios such as the emergency department for adults, ${ }^{44}$ programs aimed at a specific child population $45,49,53-55$ or referred to specialized mental health units. ${ }^{51,56}$

The ACE screening strategy described in some papers integrates actions such as training those who interact with children and their caregivers as agents sensitive to stress and childhood trauma, the application of screening tools and the reception of identified cases. ${ }^{41,44,45,49,54-56}$

Regarding the research of the ACEs, it explores both the current situation of the child and his family and the history of adversities. ${ }^{45,54,55,60}$ Two of the articles ${ }^{56,59}$ refer to a screening in two generations, in which the caregiver answers questions about his own childhood experience, and subsequently about those ACEs that the child at his charge has faced. Evidence suggests that data from the total number of ACE, rather than identifying each, can promote more accurate responses from caregivers. ${ }^{47}$

The periodicity with which the screening is implemented varies. Also, it considers screening the ACEs as part of the pediatric controls, ${ }^{41}$ the admission of a child to a program, ${ }^{45}$ in the first months after an event, ${ }^{47,54}$ when detecting alarm signs in the child behavior, ${ }^{49}$ or in the presence of conditions that could constitute adversities 


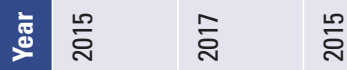

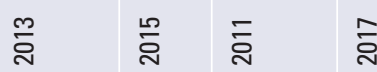

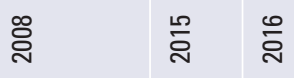

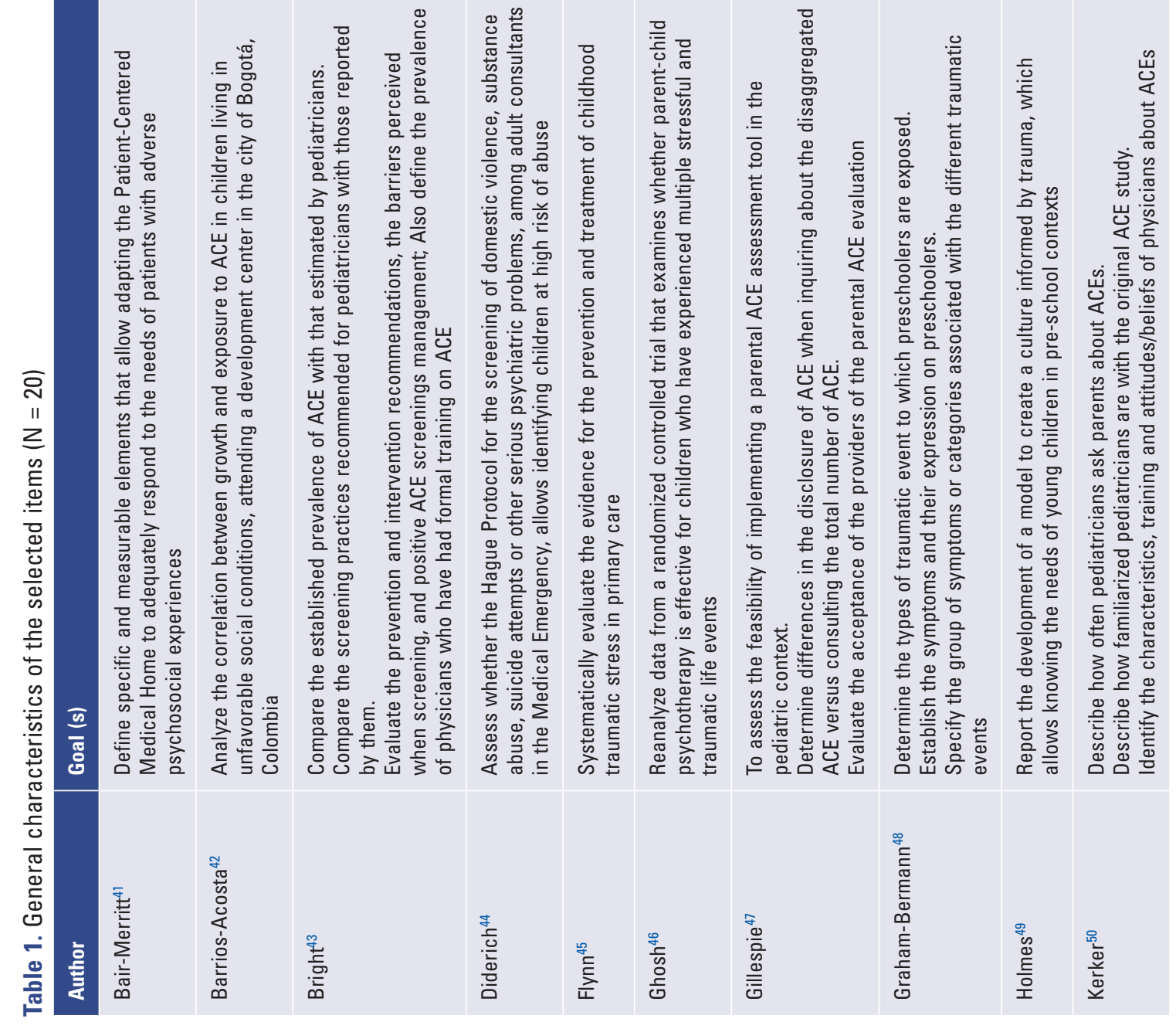



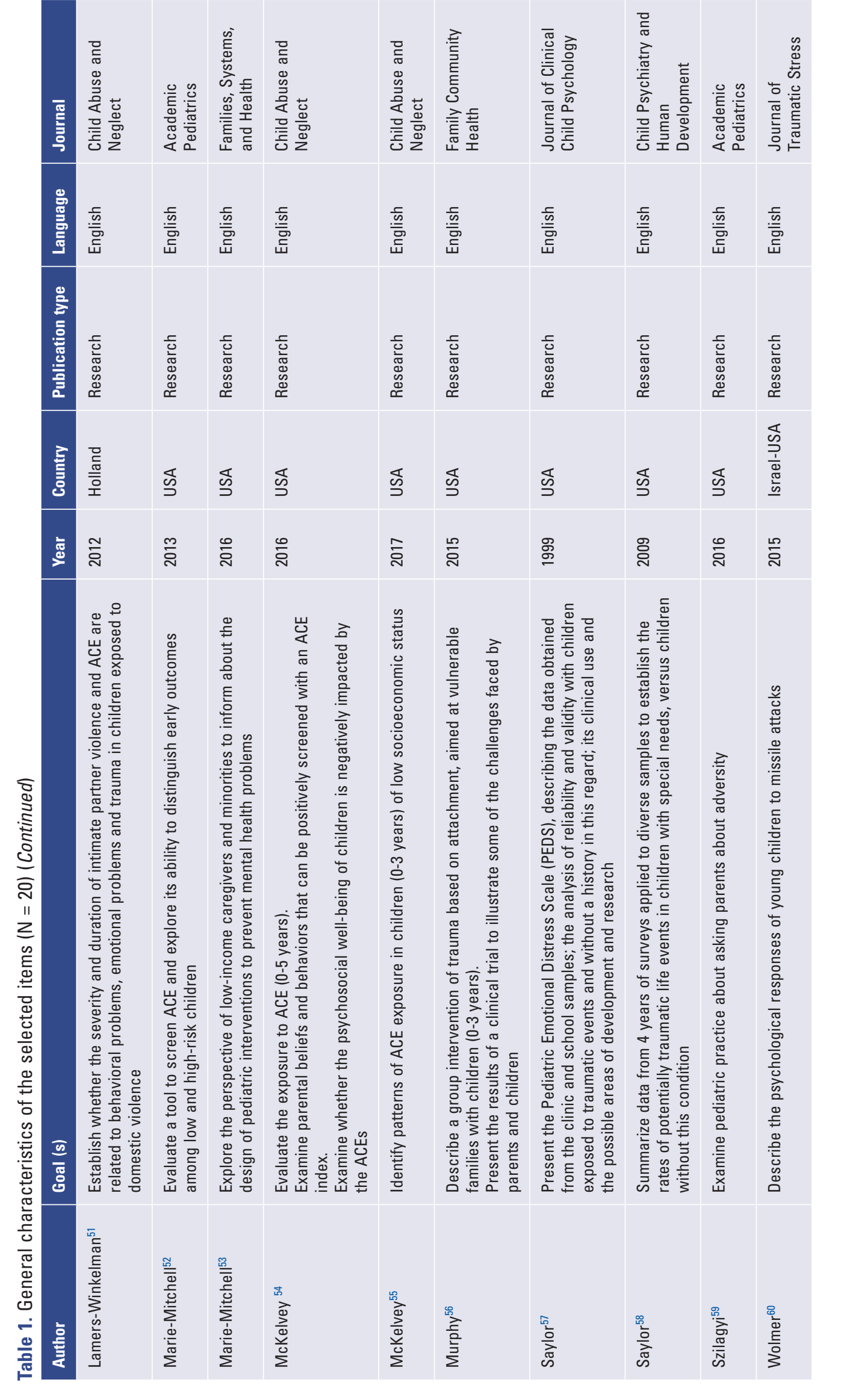


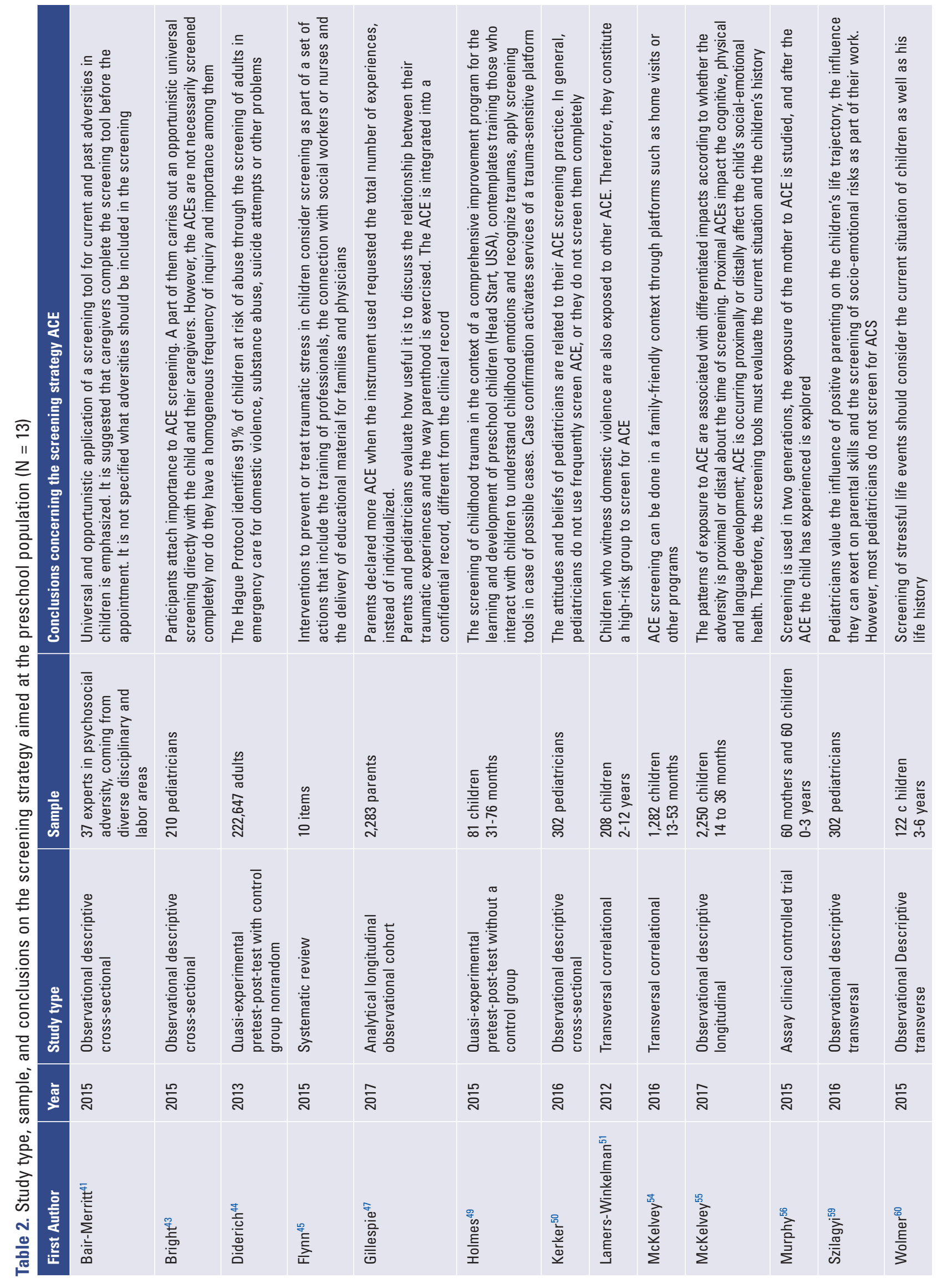


for children, such as war contexts ${ }^{60}$ or problems that involve their caregivers. ${ }^{44,51,56}$ This topic is highlighted in the Hague Protocol, ${ }^{44}$ intended to investigate domestic violence, substance abuse, attempted suicide or other serious psychiatric problems among adult consultants in the medical emergency. Ninety-one percent of the cases identified through this protocol was confirmed, revealing a high predictive value and a notable increase in the detection of cases in the Dutch regions in which it is applied.

Among the behaviors and beliefs of professionals about screening, it is established that the importance attributed to ACEs does not necessarily imply that they will be consulted. ${ }^{43,59}$ Also, the frequency of search for ACE is different. For example, it asks more for divorce than for the imprisonment of a family member. ${ }^{43}$ On the other hand, the generation of rapport among the examiner and the caregivers is highlighted as a way to identify ACE and favor parental commitment to their child well-being. ${ }^{43,54,56}$ Similarly, feedback to those who screen, indicating whether the case was confirmed or not, is associated with the motivation of the professionals in this process. ${ }^{44}$

Barriers to the screening process are often not reported. However, in the study by Bright et al., ${ }^{43}$ a reference is made to the lack of resources, lack of instruments, and the overload of screening that must be carried out.

The harmful effects of screening are not reported among the selected articles.

\section{ACE screening tools}

In the selected articles, all the tools screen for children's adversities through consultation with the responsible adult, ${ }^{42-60}$ although it is also valid to address the issue directly with the children..$^{43}$ Screening is carried out based on interviews $43,50,53,59,60$ or through questionnaires. ${ }^{42,44-46,48,52-58}$ Table 3 describes the questionnaires used in the articles to screen ACE in the preschool population.

Screening conducted through open or semi-structured interviews is widely used, ${ }^{43,50,53,59,60}$ but it may be associated with an increased risk of bias on the part of the person applying the tool. On the other hand, the questionnaires are differentiated between those that address adversities, such as the risk of child abuse or drug abuse by caregivers, ${ }^{44-46,48,57,58}$ and those specifically designed to inquire about the ACE. ${ }^{42,52-56}$ In the case of the former, their use is combined with information from sources such as records of the child's history and, together with the information provided by the instrument itself, allow the reconstruction of the categories of the ACE parameter by dichotomizing the presence or absence of adversities, and add them to obtain the number of childhood adversities. ${ }^{46}$ Although the questionnaires designed to investigate directly in the ACE in preschool children ${ }^{42,47,52-55}$ come from the definitions of the seminal study,,${ }^{9,20}$ complemented by the scientific evidence related to the topic. ${ }^{61}$ From them, the Child-ACEs ${ }^{52,53}$ and the FMI-ACEs ${ }^{54,55}$ have proven to be tools with validity and sensitivity to screen high-risk children: in the context of pediatric care in the first case, and of home visits in the second. ${ }^{61}$

\section{Discussion}

During the last decades, the study of ACE in preschoolers has generated a growing interest that is supported by the progressive increase of articles identified as of 2013. The results of the systematic exploratory review around the screening of ACEs in preschool children lead to conclude that this is an emerging topic at the research level, but still in progressive development. This fact contrasts with a large number of approaches to the subject reported in book chapters, ${ }^{62}$ unindexed journals, ${ }^{63}$ broadcast and other resources, such as posters. ${ }^{64}$

The selected articles describe some strategies and tools that can help prevent the child's entry into an escalation of risks, through early detection. In general terms, ACE screening responds to the principles for the identification of social determinants, ${ }^{31}$ but without yet forming a chain of evidence that supports the process from the research to the proven reduction in morbidity and associated mortality. Moreover, in recent years, new tools are being used to screen ACE in preschool children, which open the possibility to obtain empirical data that could permit evidence-based decision-making. Similarly, the design, implementation, and evaluation of screening in other contexts, such as education, where there is daily contact between professionals, children, and their caregivers, can promote an alliance that enhances good results.

The limited number of Latin American research on the topic leads us to suppose that this issue represents a challenge. The design of strategies and the use of culturally adapted tools, implemented in a collaborative framework that anticipates the emerging care requirements resulting from screening, is an imperative need 
Table 3. Description of the questionnaires used to screen ACE in preschoolers $(N=11)$

\begin{tabular}{|c|c|c|c|}
\hline First author & Name of the tool & Overview tool & Purpose of the tool \\
\hline Barrios-Acosta ${ }^{42}$ & ACE-Plus & $\begin{array}{l}12 \text { questions questionnaire } \\
\text { aimed at parents }\end{array}$ & $\begin{array}{l}\text { Based on the ACE questionnaire } \\
\text { developed by Dong et al. }{ }^{20} \text { adds two } \\
\text { articles: (a) Maternal consumption of } \\
\text { alcohol or drugs in pregnancy and } \\
\text { (b) Child or siblings under state } \\
\text { protection measures before evaluation }\end{array}$ \\
\hline Diderich $^{44}$ & CARE-nl & $\begin{array}{l}18 \text { questions questionnaire } \\
\text { aimed at caregiver of children } \\
\text { aged } 0 \text { - } 18 \text { years }\end{array}$ & $\begin{array}{l}\text { Risk assessment of child abuse that } \\
\text { inquires factors from parents, child, the } \\
\text { relationship between them, and from the } \\
\text { rest of the family }\end{array}$ \\
\hline Flynn $^{45}$ & $\begin{array}{l}\text { Parent Screening } \\
\text { Questionnaire (PSQ) }\end{array}$ & $\begin{array}{l}\text { Self-report } 20 \text { questions } \\
\text { questionnaire aimed at parents } \\
\text { of children between } 0-5 \text { years }\end{array}$ & $\begin{array}{l}\text { Evaluates safety, exposure to domestic } \\
\text { violence, drugs abuse by the caregiver, } \\
\text { maternal depression, and parental stress }\end{array}$ \\
\hline Flynn ${ }^{45}$ & $\begin{array}{l}\text { Pediatric Symptom } \\
\text { Checklist (PSC) }\end{array}$ & $\begin{array}{l}35 \text { questions questionnaire for } \\
\text { parents of children between } 4 \\
\text { and } 16 \text { years }\end{array}$ & $\begin{array}{l}\text { For the recognition of children with } \\
\text { cognitive, emotional and behavioral } \\
\text { problems }\end{array}$ \\
\hline Flynn $^{45}$ & WE CARE & $\begin{array}{l}\text { Self-report ten questions } \\
\text { questionnaire aimed at parents }\end{array}$ & $\begin{array}{l}\text { Screen psychosocial problems that } \\
\text { affect family: alcohol abuse, child } \\
\text { care, depression, domestic } \\
\text { violence, drug abuse, the risk of losing } \\
\text { their home, low education, inadequate } \\
\text { food supply, cigarette consumption, } \\
\text { unemployment }\end{array}$ \\
\hline Graham-Bermann ${ }^{48}$ & $\begin{array}{l}\text { The Preschool } \\
\text { Posttraumatic Stress } \\
\text { Symptoms } \\
\text { Inventory (PPSSI) }\end{array}$ & $\begin{array}{l}\text { Open-ended questions } \\
\text { questionnaire and } 17 \text { articles } \\
\text { for caregivers of preschool } \\
\text { children. }\end{array}$ & $\begin{array}{l}\text { Screens the symptoms of post-traumatic } \\
\text { stress disorder (PTSD) that preschoolers } \\
\text { can present }\end{array}$ \\
\hline Lamers-Winkelman ${ }^{51}$ & $\begin{array}{l}\text { Trauma Symptom } \\
\text { Checklist for Young } \\
\text { Children (TSCYC) }\end{array}$ & $\begin{array}{l}90 \text { direct questions } \\
\text { questionnaire aimed at } \\
\text { caregivers }\end{array}$ & $\begin{array}{l}\text { Screens the symptoms of post-traumatic } \\
\text { stress disorder (PTSD) that children } \\
\text { between } 3 \text { and } 12 \text { years can present }\end{array}$ \\
\hline Marie-Mitchell ${ }^{52,53}$ & Child ACE Tool (C-ACE) & $\begin{array}{l}41 \text { questions questionnaire } \\
\text { aimed at caregivers }\end{array}$ & Explores the ACE of $4-5$ years children \\
\hline McKelvey ${ }^{54,55}$ & $\begin{array}{l}\text { Family Map Inventory } \\
\text { ACEs (FMI-ACEs) }\end{array}$ & $\begin{array}{l}\text { Nine questions questionnaire } \\
\text { aimed at caregivers }\end{array}$ & Explores the ACE of 1-4 years children \\
\hline Murphy ${ }^{56}$ & ACE questionnaire & $\begin{array}{l}\text { Questionnaire that examines } \\
\text { ten categories of ACE in adults }\end{array}$ & $\begin{array}{l}\text { It is used to screen ACE in adults, and } \\
\text { also for these, in their role as } \\
\text { caregivers, to account for the ACE that } \\
\text { the child has suffered }\end{array}$ \\
\hline Saylor ${ }^{57.58}$ & $\begin{array}{l}\text { The Pediatric Emotional } \\
\text { Distress Scale for Young } \\
\text { Children Exposed to } \\
\text { Traumatic Events (PEDS) }\end{array}$ & $\begin{array}{l}\text { Questionnaire with } 21 \text { questions } \\
\text { directed at caregivers of } \\
\text { children between } 2-10 \text { years }\end{array}$ & $\begin{array}{l}\text { Evaluates the general child behavior and } \\
\text { his symptoms associated with childhood } \\
\text { trauma }\end{array}$ \\
\hline
\end{tabular}

for the commitment to comprehensive health for all children, particularly for preschoolers, since the effect of the ACE are more harmful at this stage of life. ${ }^{65}$

Finally, we agree with the ideas of Van Neil et al.:66 the screening of ACE in boys and girls can have multiple benefits, including strengthening ties with the family to build a resilient environment against adversity. However, it is necessary to understand it as a resource in favor of child welfare, and not as an instrument for the pathologization of childhood.

\section{Ethical disclosures}

Protection of human and animal subjects. The authors declare that no experiments were performed on humans or animals for this study.

Confidentiality of data. The authors declare that they have followed the protocols of their work center on the publication of patient data.

Right to privacy and informed consent. The authors declare that no patient data appear in this article. 


\section{Conflict of interest}

The authors declare no conflicts of interest.

\section{References}

1. Danese A, McEwen BS. Adverse childhood experiences, allostasis, allostatic load, and age-related disease. Physiol Behav. 2012;106:29-39. Available at: $h t t p: / / d x$.doi.org/10.1016/j.physbeh.2011.08.019.

2. Mouesca JP. Prevención del maltrato infantil: función del pediatra. 1ra. parte: Aspectos generales, evidencia, factores de riesgo, factores protectores y desencadenantes. Arch Argent Pediatr. 2015;113:558-67.

3. Pinheiro PS. World report on violence against children. Geneva: United Nations Publishing Services; 2006.

4. Turner HA, Finkelhor D, Ormrod R. Poly-victimization in a national sample of children and youth. AMEPRE. 2010;38:323-30. Available at: http:// dx.doi.org/10.1016/j.amepre.2009.11.012

5. Dube SR, Felitti VJ, Dong M, Chapman DP, Giles WH, Anda RF. Childhood abuse, neglect, and household dysfunction and the risk of illicit drug use: the adverse childhood experiences study. Pediatrics. 2003;111: 564-72.

6. Cronholm PF, Forke CM, Wade R, Bair-Merritt MH, Davis M, Harkins-Schwarz M, et al. Adverse Childhood Experiences. Expanding the concept of adversity. Am J Prev Med. 2015;49:354-61. Available at: http://dx.doi.org/10.1016/j.amepre.2015.02.001.

7. Finkelhor D, Shattuck A, Turner H, Hamby S. A revised inventory of Adverse Childhood Experiences. Child Abuse Negl. 2015;48:13-21.

8. Campbell JA, Walker RJ, Egede LE. Associations between adverse childhood experiences, high-risk behavior, and morbidity in adulthood. Am J Prev Med. 2016;50:344-52. Available at: http://dx.doi.org/10.1016/j.amepre.2015.07.022.

9. Felitti VJ, Anda RF, Nordenberg D, Williamson DF, Spitz AM, Edwards V, et al. Relationship of childhood abuse and household dysfunction to many of the leading causes of death in adults: The Adverse Childhood Experiences (ACE) study. Am J Prev Med. 1998;14:245-58.

10. Holman DM, Ports KA, Buchanan ND, Hawkins NA, Merrick M, Metzler M, et al. The association between Adverse Childhood Experiences and risk of cancer in adulthood: a systematic review of the literature. Pediatrics. 2016;138:s81-91.

11. Huang H, Yan P, Shan Z, Chen S, Li M, Luo C, et al. Adverse Childhood Experiences and risk of type 2 diabetes: a systematic review and meta-analysis. Metabolism. 2015;64:1408-18. Available at: http://dx.doi.org/10.1016/j.metabol.2015.08.019.

12. Mandelli $L$, Petrelli $C$, Serretti $A$. The role of specific early trauma in adult depression: A meta-analysis of published literature. Childhood trauma and adult depression. Eur Psych. 2015;30:665-80. Available at: http:// dx.doi.org/10.1016/j.eurpsy.2015.04.007.

13. Brockie TN, Dana-Sacco G, Wallen GR, Wilcox HC, Campbell JC. The relationship of Adverse Childhood Experiences to PTSD, depression, poly-drug use and suicide attempt in reservation-based Native American adolescents and young adults. Am J Community Psychol. 2015;55:411-21. Available at: http://dx.doi.org/10.1007/s10464-015-9721-3.

14. Varese F, Smeets F, Drukker M, Lieverse R, Lataster T, Viechtbauer W, et al. Childhood adversities increase the risk of psychosis: a meta-analysis of patient-control, prospective-and cross-sectional cohort studies. Schizophr Bull. 2012;38:661-71.

15. Anda RF, Butchart A, Felitti VJ, Brown DW. Building a framework for global surveillance of the public health implications of Adverse Childhood Experiences. Am J Prev Med. 2010;31:93-8. Available at: http://dx.doi. org/10.1016/j.amepre.2010.03.015.

16. Iniguez K, Stankowski R. Adverse Childhood Experiences and health in adulthood in a rural population-based sample. Clin Med Res. 2016;14:126-37.

17. Grasso DJ, Ford JD, Briggs-Gowan MJ. Early life trauma exposure and stress sensitivity in young children. J Pediatr Psychol. 2012;38:94-103. Available at: http://jpepsy.oxfordjournals.org/content/early/2012/09/23/ jpepsy.jss101.abstract.

18. childhealthdata.org [Internet]. National Center for Health US. National Survey of Children's Health. 2011. Available at: http://www.childhealthdata.org/learn/NSCH.

19. Eslinger JG, Sprang G, Otis M. Children with multi-trauma histories: special considerations for care and implications for treatment selection. J Child Fam Stud. 2015;24:2757-68.

20. Dong M, Anda RF, Felitti VJ, Dube SR, Williamson DF, Thompson TJ, et al. The interrelatedness of multiple forms of childhood abuse, neglect, and household dysfunction. Child Abuse Negl. 2004:28:771-84.

21. Bellis MA, Lowey H, Leckenby N, Hughes K, Harrison D. Adverse childhood experiences: retrospective study to determine their impact on adult health behaviours and health outcomes in a UK population. J Public Health (Bangkok). 2013;36:81-91.
22. McDonnell CG, Valentino K. Intergenerational effects of childhood trauma: evaluating pathways among maternal ACEs, perinatal depressive symptoms, and infant outcomes. Child Maltreat. 2016;21:317-26.

23. Steele $\mathrm{H}$, Bate J, Steele M, Dube SR, Danskin K, Knafo H, et al Adverse Childhood Experiences, poverty, and parenting stress. Can J Behav Sci. 2016;48:32-8.

24. Pasalich DS, Cyr M, Zheng Y, Mcmahon RJ, Spieker SJ. Child abuse history in teen mothers and parent-child risk processes for offspring externalizing problems. Child Abuse Negl. 2016;56:89-98. Available at: http://dx.doi.org/10.1016/j.chiabu.2016.04.011

25. Szilagyi M, Halfon N. Pediatric Adverse Childhood Experiences: implications for life course health trajectories. Acad Pediatr. 2015;15:467-8. Available at: http://dx.doi.org/10.1016/j.acap.2015.07.004.

26. Mason DJ, Cox K. Toxic stress in childhood: Why we all should be concerned. Nurs Outlook. 2014;62:382-3. Available at: http://dx.doi.org/10.1016/j.outlook.2014.09.001.

27. Vega-Arce M, Núñez-Ulloa G. Experiencias adversas en la infancia: revisión de su impacto en niños de 0 a 5 años. Enfermería Univ. 2017;14:124-30.

28. Schore EL, American Academy of Pediatrics Task Force on the Family. Family pediatrics: report of the Task Force on the Family. Pediatrics. 2003:111:1541-71.

29. Raffle AE, Gray JAM. Screening: evidence and practice. Oxford: Oxford University Press; 2007. pp. 366.

30. Kisiel C, Conradi L, Fehrenbach T, Torgersen E, Briggs EC. Assessing the effects of trauma in children and adolescents in practice settings. Child Adolesc Psychiatr Clin N Am. 2014;23:223-42.

31. Chung EK, Siegel BS, Garg A, Conroy K, Gross RS, Long DA, et al. Screening for social determinants of health among children and families living in poverty : a guide for clinicians. Curr Probl Pediatr Adolesc Health Care. 2016;46:135-53. Available at: http://dx.doi.org/10.1016/j. cppeds.2016.02.004

32. Domitrovich CE, Cortes RC, Greenberg MT. Improving young children's social and emotional competence : a randomized trial of the preschool "PATHS" Curriculum. J Prim Prev. 2007;28:67-91.

33. Shonkoff JP, Garner AS, The Committee on Psychosocial Aspects of Child and Family Health, Committee on Early Childhood, Adoption, and Dependent Care and Section on Developmental and Behavioral Pediatrics. The lifelong effects of early childhood adversity and toxic stress. Pediatrics. 2012;129:e231-46.

34. Garg A, Dworkin PH. Applying surveillance and screening to family psychosocial issues : implications for the Medical Home. J Dev Behav Pediatr. 2011;32:418-26.

35. Olson-Dorff D. Application of Adverse Childhood Experiences research into health care at Gundersen Health System : addressing the social determinants of health. J Child Adolesc Trauma. 2017;1-4.

36. Bucci M, Silvério S, Oh D, Harris NB. Toxic stress in children and adolescents. Adv Pediatr. 2016:63:403-28.

37. Arksey H, O'Malley L. Scoping studies: towards a methodological framework. Int J Soc Res Methodol Theory Pract. 2005;8:19-32.

38. Manchado R, Tamames S, López M, Mohedano L, D’Agostino M Veiga J. Revisiones sistemáticas exploratorias. Med Segur-Trab (Madrid). 2009;55:12-9.

39. Ritchie J, Spencer L. Qualitative data analysis for applied policyresearch. In: Bryman A, Burgess RG, editors. Analyzing Qualitative Data. London, UK: Routledge; 2002. pp. 173-94

40. McGilton KS, Höbler F, Campos J, Dupuis K, Labreche T, Guthrie DM, et al. Hearing and vision screening tools for long-term care residents with dementia: protocol for a scoping review. BMJ Open. 2016;6:e011945.

41. Bair-Merritt M, Mandal M, Garg A, Cheng TL. Addressing psychosocial adversity within the Patient-Centered Medical Home : expert-created measurable standards. J Prim Prev. 2015;36:213-25. Available at: http:/ dx.doi.org/10.1007/s10935-015-0390-7.

42. Barrios-Acosta M, Riaño-Rondón SV, Villa-Rosero YM, Martínez OP, Aragón-Joya YA, Mayer S. Correlation between growth and adverse childhood experiences in vulnerable children in Bogotá, Colombia. J Child Adolesc Trauma. 2017;1-8.

43. Bright MA, Jenssen DE, Alford S. Primary care pediatricians' perceived prevalence and surveillance of Adverse Childhood Experiences in low-income children. J Health Care Poor Underserved. 2015;26:686-700.

44. Diderich $\mathrm{HM}$, Fekkes $\mathrm{M}$, Verkerk $\mathrm{PH}$, Pannebakker FD, Klein M Sorensen PJG, et al. A new protocol for screening adults presenting with their own medical problems at the Emergency Department to identify children at high risk for maltreatment. Child Abuse Negl. 2013;37:1122-31. Available at: http://dx.doi.org/10.1016/j.chiabu.2013.04.005

45. Flynn AB, Fothergill KE, Wilcox HC, Coleclough E, Horwitz R, Ruble A, et al. Primary care interventions to prevent or treat traumatic stress in childhood : a systematic review. Acad Pediatr. 2015;15:480-92.

46. Ghosh C, Harris WW, Horn P Van, Lieberman AF. Traumatic and stressful events in early childhood: can treatment help those at highest risk? Child Abuse Negl. 2011;35:504-13. Available at: http://dx.doi.org/10.1016/j.chiabu.2011.03.009. 


\section{Vega-Arce, G. Núñez-Ulloa: Screening of adverse experiences in preschoolers}

47. Gillespie RJ, Folger AT. Feasibility of assessing parental ACEs in pediatric primary care : implications for practice-based implementation. J Child Adolesc Trauma. 2017;1-8.

48. Graham-Bermann SA, Howell K, Habarth J, Krishnan S, Loree A, Bermann EA. Toward assessing traumatic events and stress symptoms in preschool children from low-income families. Am J Orthopsychiatry. 2008;78:220-8.

49. Holmes C, Levy M, Smith A, Pinne S, Neese P. A model for creating a supportive trauma-informed culture for children in preschool settings. J Child Fam Stud. 2015;24:1650-9.

50. Kerker BD, Storfer-Isser A, Szilagyi MA, Stein REK, Garner AS, Connor KGO, et al. Do pediatricians ask about Adverse Childhood Experiences in pediatric primary care? Acad Pediatr. 2016;16: 154-61.

51. Lamers-Winkelman F, Willemen AM, Visser M. Childhood Experiences of referred children exposed to intimate partner violence: consequences for their wellbeing. Child Abuse Negl. 2012;36:166-79. Available at: http:// dx.doi.org/10.1016/j.chiabu.2011.07.006.

52. Marie-Mitchell A, Connor TGO. Adverse Childhood Experiences: translating knowledge into identification of children at risk for poor outcomes. Acad Pediatr. 2013;13:14-20.

53. Marie-Mitchell A, Studer KR, Connor TGO. How knowledge of Adverse Childhood Experiences can help pediatricians prevent mental health problems. Fam Syst Heal. 2016;34:128-35.

54. McKelvey LM, Whiteside-Mansell L, Conners-Burrow NA, Swindle T, Fitzgerald S. Assessing Adverse Experiences from infancy through early childhood in home visiting programs. Child Abus Negl. 2016;51: 295-302.

55. McKelvey LM, Selig JP, Whiteside-Mansell L. Foundations for screening adverse childhood experiences: exploring patterns of exposure through infancy and toddlerhood. Child Abuse Negl. 2017;70:112-21. Available at: http://dx.doi.org/10.1016/j.chiabu.2017.06.002.

56. Murphy A, Steele H, Bate J, Nikitiades A, Allman B, Bonuck K, et al. Group attachment-based intervention: trauma-informed care for families with Adverse Childhood Experiences. Fam Community Health. 2015;38: 268-79.
57. Saylor CF, Cupit C, Stokes S, Taylor M. The pediatric emotional distress scale: a brief screening measure for young children exposed to traumatic events. J Clin Child Psychol. 1999;28:70-81.

58. Saylor CF, Macias M, Wohlfeiler M, Morgan L, Awkerman N. Exposure to potentially traumatic life events in children with special needs. Child Psychiatry Hum Dev. 2009;40:451-65.

59. Szilagyi M, Kerker BD, Storfer-Isser A, Stein REK, Garner A, Connor KGO, et al. Factors associated with whether pediatricians inquire about parents' Adverse Childhood Experiences. Acad Pediatr. 2016;16:668-75. Available at: http://dx.doi.org/10.1016/j.acap.2016.04.013.

60. Wolmer L, Hamiel D, Versano-Eisman T, Slone M, Margalit N, Laor N, et al. Preschool Israeli children exposed to rocket attacks: assessment, risk, and resilience. J Trauma Stress. 2015;28:441-7.

61. Finkelhor D, Shattuck A, Turner H, Hamby S. Improving the Adverse Childhood Experiences study scale. Arch Pediatr Adolesc Med. 2013;167:1-6.

62. Murphy A, Steele H, Steele M, Allman B, Kastner T, Dube SR. The clinical Adverse Childhood Experiences (ACEs) Questionnaire: Implications for Trauma-Informed Behavioral Healthcare. In: Rahil D. Briggs, editor. Integrated early childhood behavioral health in primary care. Bronx: Springer International Publishing; 2016. pp. 7-17.

63. Purewal S, Bucci M, Gutiérrez L, Koita K, Silvério S, Oh D, et al Screening for Adverse Childhood Experiences (ACEs) in an integrated pediatric care model. Zero Three. 2016;37:10-7.

64. Seo-Lee A, Bayldon B, Ruiz M, Fujara M, Aschkenasy J, DiGiacomo M. Piloting a screening tool for social determinants of health, Adverse Childhood Experiences (ACEs), and resiliency among children seen in 4 urban resident clinics. American Academy of Pediatrics. National Conference and Exhibition. (October, 2015).

65. Schalinski I, Teicher MH, Nischk D, Hinderer E, Müller O, Rockstroh B. Type and timing of adverse childhood experiences differentially affect severity of PTSD, dissociative and depressive symptoms in adult inpatients. BMC Psychiatry. 2016;16:295. Available at: http://dx.doi. org/10.1186/s12888-016-1004-5.

66. Van Niel C, Pachter LM, Wade R, Felitti VJ, Stein MT. Adverse Events in Children: predictors of adult physical and mental conditions. J Dev Behav Pediatr. 2014;35:549-51. 